\title{
Excess of serotonin affects neocortical pyramidal neuron migration
}

\author{
O Riccio ${ }^{1,2,3}$, M Jacobshagen ${ }^{1,2,3}$, B Golding ${ }^{2,3}$, L Vutskits ${ }^{2,3,4}$, D Jabaudon ${ }^{2,3,5}$, JP Hornung ${ }^{6}$ and AG Dayer ${ }^{1,2,3}$
}

The serotonin transporter (SERT) is a key molecule involved in the homeostasis of extracellular levels of serotonin and is regulated developmentally. Genetic deletion of SERT in rodents increases extracellular levels of serotonin and affects cellular processes involved in neocortical circuit assembly such as barrel cortex wiring and cortical interneuron migration. Importantly, pharmacological blockade of SERT during brain development leads to phenotypes relevant to psychiatry in rodents and to an increased risk for autism spectrum disorders in humans. Furthermore, developmental adversity interacts with genetically-driven variations of serotonin function in humans and nonhuman primates to increase the risk for a variety of stress-related phenotypes. In this study, we investigate whether an excess of serotonin affects the migration of neocortical pyramidal neurons during development. Using in utero electroporation combined with time-lapse imaging to specifically monitor pyramidal neurons during late mouse embryogenesis, we show that an excess of serotonin reversibly affects the radial migration of pyramidal neurons. We further identify that the serotonin receptor $5-\mathrm{HT}_{6}$ is expressed in pyramidal neuron progenitors and that $5-\mathrm{HT}_{6}$ receptor activation replicates the effects of serotonin stimulation. Finally, we show that the positioning of superficial layer pyramidal neurons is altered in vivo in SERT knockout mice. Taken together, these results indicate that a developmental excess of serotonin decreases the migration speed of cortical pyramidal neurons, affecting a fundamental step in the assembly of neural circuits. These findings support the hypothesis that developmental dysregulation of serotonin homeostasis has detrimental effects on neocortical circuit formation and contributes to increased vulnerability to psychiatric disorders.

Translational Psychiatry (2011) 1, e47; doi:10.1038/tp.2011.49; published online 11 October 2011

\section{Introduction}

Vulnerability to psychiatric disorders is likely to have an early developmental origin. Understanding the molecular mechanisms controlling the assembly of cortical circuits and how abnormal neocortical circuit formation leads to psychiatric disorders is a fundamental question. ${ }^{1}$ Neuronal migration is a critical early step in the construction of cortical circuits, ultimately determining the cell-subtype-specific positioning of differentiating neurons in the distinct cortical layers. ${ }^{2}$ Abnormal positioning of the distinct subtypes of neurons is likely to impair the subsequent establishment of interneuronal connectivity and the function of cortical circuits. ${ }^{3}$ Inhibitory interneurons and excitatory projection neurons are born in different regions of the telencephalon, and their migration is largely determined by the combinatorial expression of different sets of transcription factors. ${ }^{2}$ Projection neurons are generated in the ventricular zone (VZ) of the developing pallium and migrate radially to reach their final laminar position. ${ }^{2}$ In contrast, inhibitory interneurons mainly originate from the ganglionic eminences of the subpallium and migrate first tangentially toward the pallium before radially invading the cortical plate. ${ }^{2}$ Several genetic networks controlling neuronal diversity and migration are associated with developmental and adult psychiatric disorders. ${ }^{3}$ Among these signaling networks, the serotonergic system has been shown to regulate cellular events critical for the proper assembly of neural circuits, ${ }^{4}$ such as thalamocortical wiring ${ }^{5}$ and neuronal migration. ${ }^{6}$ A regulatory role for serotonin in cell migration is observed in non-neuronal cells such as eosinophils in the immune system, ${ }^{7}$ pulmonary artery smooth muscle cells, ${ }^{8}$ aortic smooth muscle cells, ${ }^{9}$ aortic endothelial cells ${ }^{10}$ and mesenchymal cells. ${ }^{11}$ In the developing nervous system, both excess of serotonin resulting from the deletion of the serotonin transporter (SERT) ${ }^{6}$ and depletion of serotonin ${ }^{12,13}$ impair interneuron migration. Understanding the role of serotonin during cortical circuit formation is relevant for psychiatric disorders for several reasons. First, at a behavioral level, SERT blockade during the prenatal or early postnatal period gives rise to stress-related phenotypes in adulthood. ${ }^{14-16}$ Second, in humans and non-human primates, a hypofunctional polymorphism (5-HTTLPR, short allele) in the promoter region of the SERT gene interacts with developmental adversity to increase the risk for affective dysregulation. ${ }^{17-23}$ Furthermore, the 5-HTTLPR s-allele is associated with specific clinical subdomains of autistic

\footnotetext{
${ }^{1}$ Department of Mental Health and Psychiatry, University Hospital of Geneva, Geneva, Switzerland; ${ }^{2}$ Department of Basic Neurosciences, University of Geneva Medical School, Geneva, Switzerland; ${ }^{3}$ Geneva Neuroscience Center, University of Geneva Medical School, Geneva, Switzerland; ${ }^{4}$ Department of Anesthesiology Pharmacology and Intensive Care, University Hospital of Geneva, Geneva, Switzerland; ${ }^{5}$ Clinic of Neurology, University Hospital of Geneva, Geneva, Switzerland and ${ }^{6}$ Department of Cellular Biology and Morphology, University of Lausanne, Lausanne, Switzerland

Correspondence: Dr AG Dayer, Department of Mental Health and General Psychiatry, University Geneva Medical Center (CMU), Rue Michel-Servet 1, 1211 Genève 4, Switzerland.
}

E-mail: alexandre.dayer@unige.ch

Keywords: autism; cortex; depression; development; migration; serotonin

Received 2 August 2011; revised 2 September 2011; accepted 5 Septemeber 2011 
deficits $^{24}$ and with increases in cerebral cortical gray matter volume in children with autism. ${ }^{25}$ Finally, recent data indicate that prenatal exposure to selective serotonin reuptake inhibitors increases the risk of developing autism spectrum disorders. ${ }^{26}$

A developmental excess of serotonin could thus critically impair the formation of neuronal circuits and increase vulnerability to a broad range of psychiatric disorders. In this study, we sought to determine whether an excess of serotonin could affect the migration of excitatory pyramidal neurons, an early developmental process necessary for the subsequent formation of neocortical circuits. ${ }^{2}$ By combining in utero electroporation with time-lapse imaging, we find that an excess of serotonin decreases the migration speed of pyramidal neurons. We report that the serotonin receptor subtype $6\left(5-\mathrm{HT}_{6}\right)$ is expressed throughout the developing cortex during the late embryonic period and that activation of the $5-\mathrm{HT}_{6}$ receptor decreases pyramidal neuron migration speed. Finally, we find that the positioning of superficial layer cortical projection neurons is altered in SERT knockout mice, indicating that an excess of serotonin can affect pyramidal neuron migration in vivo.

\section{Materials and methods}

Animals. All animal experiments were conducted in accordance with international and Swiss laws. The day of the vaginal plug detection was counted as embryonic day 0.5 (E0.5). We used wild-type C57BI/6 mice, transgenic mice expressing GFP under the control of the GAD65 promoter (GAD65-GFP mice) $^{6}$ or homozygote SERT ko mice crossed to GAD65-GFP mice, all maintained on a C57BI/6 background. $^{6}$

In utero electroporation, cortical slice preparation and time-lapse imaging. To label pyramidal neurons, embryos from timed pregnant E14.5 or E16.5, dams were electroporated in the $\mathrm{VZ}$ of the dorsal pallium with a plasmid expressing a red fluorochrome (tomato, TOM) under the regulation of the ubiquitin promoter. After in utero electroporation, dams were killed by intraperitoneal pentobarbital injection $\left(50 \mathrm{mg} \mathrm{kg}^{-1}\right)$, and embryos collected at E17.5 or E19.0. P0.5 pups were killed by rapid decapitation. Cortical slices ( $200 \mu \mathrm{m}$ thick) were cut on a vibratome, placed on porous nitrocellulose filters (Millicell-CM, Millipore, Zug, $\mathrm{CH}$ ) and kept in neurobasal medium (Invitrogen, Zug, $\mathrm{CH}$ ) supplemented with 2\% B27 (Invitrogen) as previously described. ${ }^{6}$

Cell culture experiments. To test the specificity of the $5-\mathrm{HT}_{6}$ receptor antibody, transfections were performed on $293 \mathrm{~T}$ cells using a pEGFP-5- $\mathrm{HT}_{6}$-expressing plasmid (kind gift of Dr Kirk Mykytyn) ${ }^{27}$ diluted in OptiMEM (Invitrogen) together with Lipofectamine 2000 transfection reagent (Invitrogen). To stain pyramidal neurons and GAD65-GFP + interneurons in vitro, E17.5 cortical slices from E14.5 electroporated embryos were prepared, cortices were dissected and trypsinized in Hanks' medium for 10 min at $37^{\circ} \mathrm{C}, \mathrm{TOM}+$ and GAD65-GFP + cells were isolated using fluorescence-activated cell sorting (FACS), ${ }^{6}$ platted on polyornithine-coated petri dishes (Invitrogen) and immunostained with a $5-\mathrm{HT}_{6}$ antibody at day in vitro 1 .

Tissue processing and immunohistochemistry. Animals were deeply anesthetized by pentobarbital intraperitoneal injection ( $50 \mathrm{mg} \mathrm{kg}^{-1}$ ), and killed by intracardial perfusion of $0.9 \%$ saline followed by cold $4 \%$ paraformaldehyde (PFA) (pH 7.4). Brains were post-fixed $48 \mathrm{~h}$ in $4 \%$ PFA at $4{ }^{\circ} \mathrm{C}$ and coronal sections were cut on a vibratome and stored at $4{ }^{\circ} \mathrm{C}$ in $0.1 \mathrm{M}$ phosphate-buffered saline. Free-floating immunohistochemistry on sections was performed as previously described. ${ }^{6}$ Primary antibodies were used at the following concentrations: rabbit anti-5- $\mathrm{HT}_{6}$ (1:100; Abcam, Cambridge, UK), rabbit anti-serotonin (1:5000; Sigma, Buchs, $\mathrm{CH})$ and mouse anti-acetylated tubulin (1:500; Sigma).

Image acquisition and analysis. Cortical slices were imaged in a thermoregulated chamber and time-lapse movies were acquired using a fluorescent microscope (Eclipse TE2000, Nikon, Amstelveen, NE) as previously described. ${ }^{6}$ Images were acquired using the Open-lab software (version 5.0, Waltham, MA, USA) every $10 \mathrm{~min}$ for over $16 \mathrm{~h}$. Time-lapse stacks were generated and analyzed using Metamorph software (version 7.4, Oxford, UK). TOM+ cells located in the intermediate zone and migrating radially during time-lapse sequences were selected for single-cell tracking at E17.5 and at P0.5. A total of 60-110 cells in at least three separate experiments were quantified for each experimental condition. For treatment conditions, 5- HT $400 \mu \mathrm{M}$ (Sigma, diluted in $\mathrm{H}_{2} \mathrm{O}$ ) or EMD $386088300 \mu \mathrm{M}$ (Tocris, Bristol, UK, diluted in $\mathrm{H}_{2} \mathrm{O}$ ) was applied in the bath medium during $90 \mathrm{~min}$ after a control time-lapse sequence of at least $260 \mathrm{~min}$. After washing out the drug, TOM + cells were monitored for at least $590 \mathrm{~min}$. To obtain confocal images of fluorescent-labeled cells, a Zeiss LSM 510meta confocal microscope (Zeiss, Feldbach, $\mathrm{CH}$ ) equipped with a PlanNeofluar $\times 40 / 0.50$ objective was used. To quantify the distribution of pyramidal neurons in the developing cortex, composite images of the prospective somatosensory cortex were taken at $\times 10$ using an epifluorescent microscope (Nikon Eclipse 90i). TOM + cells were counted manually using a 10bin grid generated in the Metamorph software, and apposed on the prospective somatosensory cortex of control brains ( $n=9,2254$ cells) and SERT ko brains ( $n=9,2791$ cells). Statistical analysis (GraphPad Prism software, version 4.0) was done using one-way analysis of variance with Tukey's post-hoc tests or using Student's $t$-test. Statistical significance was defined at ${ }^{\star} P<0.05$ and ${ }^{\star *} P<0.01$, ${ }^{\star \star *} P<0.001$.

RNA isolation, complementary DNA synthesis and realtime quantitative PCR. Cortical slices were prepared and cortices were dissected under a stereo microscope (Leica M165 FC, Heerbrugg, CH). Total RNA of cortical tissue from E17.5 and P0.5 was extracted using the RNeasy Mini kit (Qiagen, Hombrechtikon, $\mathrm{CH}$ ). The quality of RNA was checked on an Agilent 2100 Bioanalyser (Agilent Technologies, Basel, $\mathrm{CH}$ ) and converted into complementary DNA using standard procedures (Takara Bio, Shiga, Japan). SYBR green-based real-time PCR (Qiagen) was used to 
quantify the expression of $5-\mathrm{HT}_{6}$ receptor (forward primer: 5'-GGTGCCATCTGCTTCACCTA-3'; reverse primer: 5'-CAG CCAGGTGACAAAGAACA-3'). PCRs were performed on an ABI Prism 7900 Sequence Detection System (Applied Biosystems, Carlsbad, CA, USA). Each reaction was performed in three replicates, and two housekeeping genes were used as internal controls (beta-actin (actb) and GAPDH).

In situ hybridization. The antisense $5-\mathrm{HT}_{6}$ receptor digoxigenin-labeled RNA probe was synthesized by in vitro transcription using a DIG RNA labeling kit and T7 RNA polymerase (Roche, Rotkreuz, $\mathrm{CH}$ ). Forward primer: 5'-TCCAGGTCTCTTCGATGTCC-3' and reverse primer: 5'-CGATGTTAATACGACTCACTATAGGGCCGTATCTCAG GCTCCACAG-3' (underlined section denotes T7 promoter and linker sequence) were designed in exon 4 of the $5-\mathrm{HT}_{6}$ receptor gene. In situ hybridization was performed as previously described. ${ }^{28}$ Briefly, brains of E17.5 and P0.5 mice were dissected and fixed overnight at $4{ }^{\circ} \mathrm{C}$ in $4 \%$ PFA. Coronal sections were cut on a vibratome (50 $\mu \mathrm{M}$ thickness) and mounted on Superfrost Plus slides. Hybridization was carried out overnight at $60^{\circ} \mathrm{C}$ with the DIG-labeled RNA probe. Following hybridization, sections were washed and incubated with alkaline phosphatase-conjugated antidigoxigenin antibody (Roche $1: 2000$ ) overnight at $4{ }^{\circ} \mathrm{C}$. Following incubation, sections were washed and the color reaction was carried out overnight at $4{ }^{\circ} \mathrm{C}$ in a solution containing NBT/BCIP (Roche). After color revelation, sections were washed, post-fixed for $30 \mathrm{~min}$ in $4 \%$ PFA and mounted with Fluromount (Sigma).

\section{Results}

To monitor the migration of excitatory pyramidal neurons populating superficial cortical layers during the embryonic period, we performed in utero electroporations of a TOMexpressing plasmid in the lateral ventricles of E14.5 embryos and analyzed the cortex of electroporated embryos at different developmental time points. This method allows efficient labeling of cortical pyramidal neurons in vivo. ${ }^{29}$ After in utero electroporation at E14.5, a population of TOM + cells was located in the E17.5 intermediate zone and displayed the morphology of pyramidal neurons migrating radially toward the pial surface (Figure 1a). By E19 a large fraction of TOM + cells settled in the cortical plate in prospective layers II/III (Figure $1 \mathrm{~b}$ ). To directly visualize the migration of pyramidal neurons, we performed time-lapse imaging for at least $12 \mathrm{~h}$ in E17.5 cortical slices after E14.5 in utero electoporations (Figure 1c, Supplementary Movie 1). To more specifically target late-born layer II pyramidal neurons, in utero electroporation was performed in the lateral ventricles of E16.5 embryos. A population of TOM + pyramidal neurons with morphologies radially oriented toward the pial surface
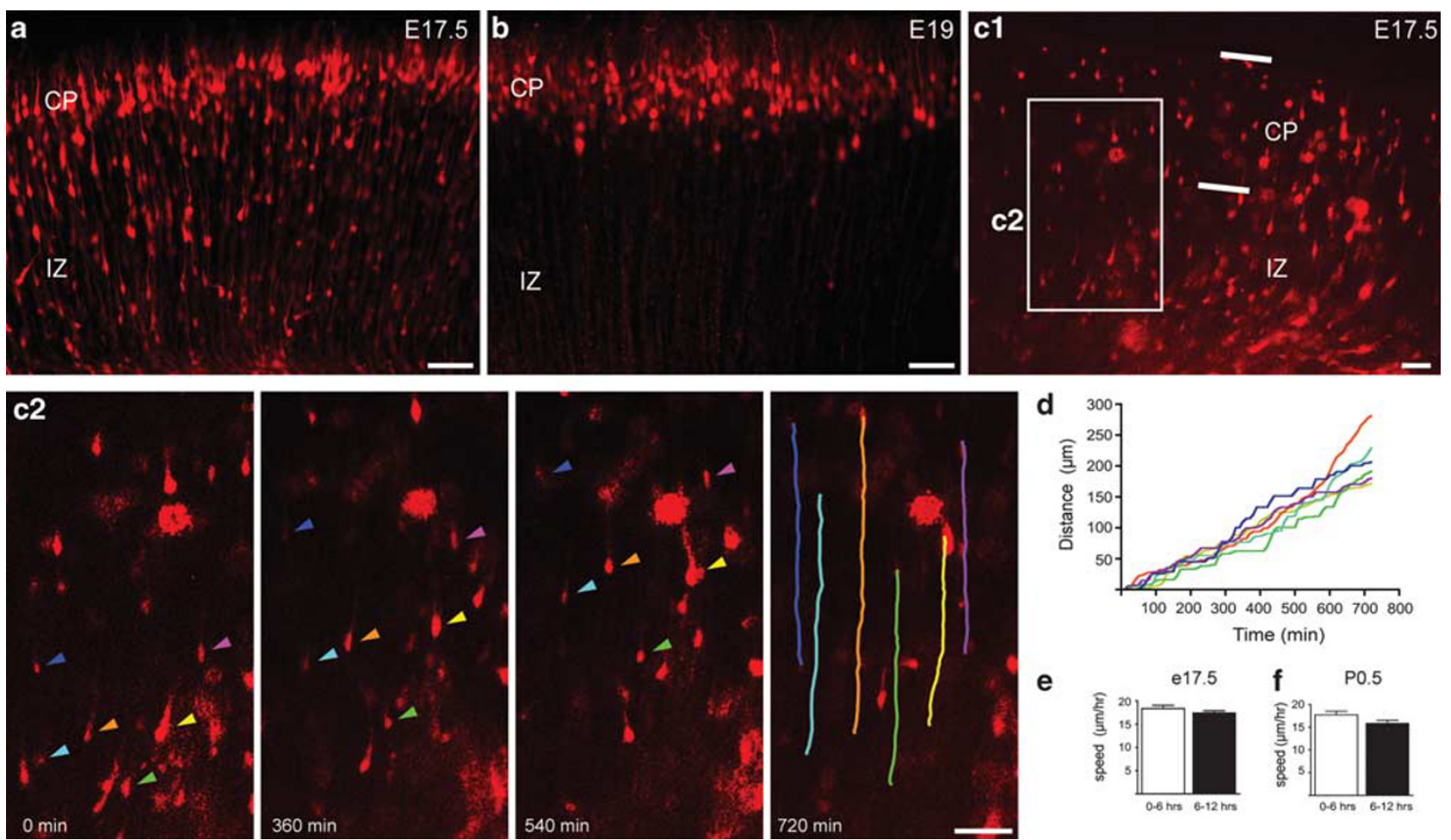

e
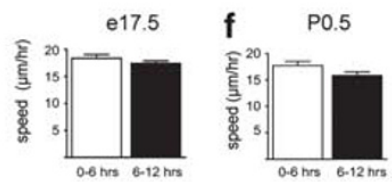

Figure 1 Time-lapse imaging of pyramidal neuron migration in cortical slices. (a, b) Confocal images showing that TOM + pyramidal neurons display radially orientated migratory-like morphologies in the E17.5 developing cortex (a) and reach their final destination in superficial cortical layers at E19 (b). Pyramidal neurons were labeled using in utero electroporation of a TOM + -expressing plasmid in the ventricular zone (VZ) at E14.5. (c) Epifluorescent time-lapse images taken from a 12-h time-lapse sequence showing TOM + neurons (arrowheads) migrating radially toward the pial surface in a E17.5 cortical slice. Superposed color lines represent migratory tracks. (d) Graph showing the migratory distances travelled by TOM + cells shown in panel c2. (e, f) Graphs showing that the mean migratory speed of TOM + cells does not significantly change during a 12-h time-lapse sequence in E17.5 TOM + cells labeled at E14.5 (e) and in P0.5 TOM + cells labeled at E17.5 (f). White boxed area depicts a higher magnification image. Scale bars: $50 \mu \mathrm{m}$. 
was observed in the intermediate zone at P0.5 (Supplementary Movie 2). TOM + cells located in the intermediate zone at E17.5 or at P0.5 were tracked during $12 \mathrm{~h}$, and no differences in the mean migratory speed were observed between $\mathrm{TOM}+$ cells migrating from 0-6 h compared with 6-12 h (Figures 1c-f; Supplementary Movies 1-2). These data indicate that in control conditions, TOM + cells migrate radially toward the pial surface and that the speed of migration is stable during the whole duration of the time-lapse sequence. Finally, to determine whether in utero electroporation targeting the dorsal pallial VZ specifically labels excitatory glutamatergic neurons and not GABAergic interneurons, in utero electroporation was performed in mice expressing GFP under the control of the GAD65-GFP promoter (Figure 2a). GAD65-GFP + cells were not co-labeled with TOM, further confirming that in utero electroporation of the embryonic dorsal pallium specifically labels excitatory neuronal precursors. ${ }^{29}$
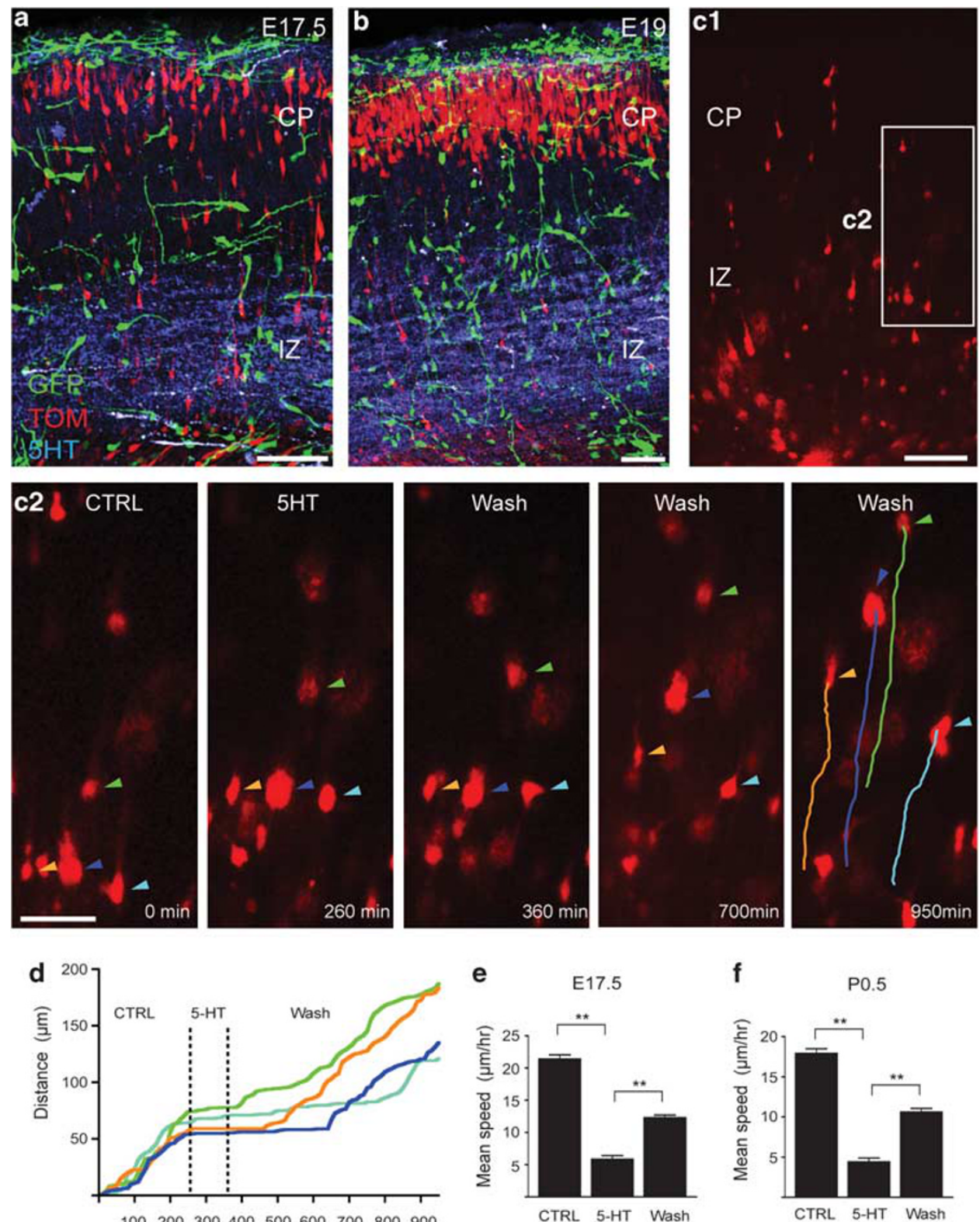

f

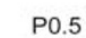

100200300400500600700800900

Time (min)

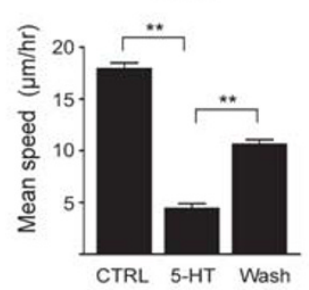

Figure 2 Serotonin decreases the migration speed of pyramidal neurons. (a, b) Confocal images showing that during the process of radial migration, 5-HT positive fibers (blue) are present in intermediate zone at E17.5 and E19.0, and that GAD65-GFP positive interneurons are not labeled by in utero electroporation. (c1) Epifluorescent timelapse images taken from a 12-h time-lapse sequence showing that application of serotonin ( $400 \mu \mathrm{M})$ slows the migration of TOM + neurons (arrowheads) in a P0.5 cortical slice, and that this effect is reversible after washing serotonin from the medium. Superposed color lines represent migratory tracks. (d) Graph showing the migratory distance traveled by TOM + cells indicated in panel c2. Note that cells halt their migration during 5-HT application and gradually resume migration after the wash. (e, f) Graphs showing that the mean migratory speed of E17.5 TOM + cells (e) and P0.5 TOM + cells (f) significantly decreases after 5 -HT application and is partially restored after 5-HT wash. White boxed area depicts a higher magnification image. ${ }^{* *} P<0.05$, GFP, GAD65-GFP. Scale bars: $100 \mu \mathrm{m}$ for $\mathbf{a}$ and $\mathbf{b}, 50 \mu \mathrm{m}$ for $\mathbf{c}$. 
Excess of serotonin decreases pyramidal neuron migration. Immunohistochemistry for serotonin $(5-\mathrm{HT})$ at E17.5 and E19.0 indicates that TOM + pyramidal neurons migrate in the vicinity of $5-\mathrm{HT}$ positive fibers located in the intermediate zone of the dorsal pallium (Figures $2 a, b$ ). To determine whether $5-\mathrm{HT}$ regulates the migration of pyramidal neurons, $\mathrm{TOM}+$ neurons migrating radially in the intermediate zone were first monitored during a control time period of $260 \mathrm{~min}$. Serotonin $(400 \mu \mathrm{M})$ was then applied during $90 \mathrm{~min}$ in the bath medium. Single-cell tracking revealed that $5-\mathrm{HT}$ significantly reduces the speed of $\mathrm{TOM}+$ neuron radial migration during its application (Figures 2c-e). This effect was observed in E17.5 TOM + cells electroporated at E14.5 and in P0.5 TOM + cells electroporated at E16.5 (Figures 2c-e, Supplementary Movies 3, 4) indicating that 5-HT regulates the migration of neocortical pyramidal neurons populating superficial cortical layers. The effect of 5-HT on pyramidal neuron migration was reversible. After washing $5-\mathrm{HT}$ from the bath medium, $\mathrm{TOM}+$ cells were monitored during $590 \mathrm{~min}$. During this time period, E17.5 and P0.5 TOM + cells gradually resumed radial migration, indicating that excess of $5-\mathrm{HT}$ does not irreversibly affect pyramidal neuron migration.

The $5-\mathrm{HT}_{6}$ receptor is expressed in pyramidal neurons during cortical development. Previous work from our lab has demonstrated that activation of the $5-\mathrm{HT}_{6}$ receptor inhibits embryonic cortical interneuron migration. ${ }^{6}$ In situ hybridization revealed that the $5-\mathrm{HT}_{6}$ receptor is expressed throughout the developing cortex at E17.5 with a stronger expression in the $\mathrm{VZ}$ and cortical plate (Figures $3 \mathrm{a}, \mathrm{b}$ ). In situ hybridization indicated that $5-\mathrm{HT}_{6}$ receptor expression persists in the developing cortex at birth, with a stronger signal in superficial cortical layers (Figure 3c). Quantitative PCR performed on mRNA extracted from E17.5 and P0.5 cortices confirmed that the $5-\mathrm{HT}_{6}$ receptor is expressed in the developing cortex (Figure 3d). To determine whether $\mathrm{TOM}+$ pyramidal neurons expressed the $5-\mathrm{HT}_{6}$ receptor, $\mathrm{E} 17.5 \mathrm{TOM}+$ cells electroporated at E14.5 were dissected from E17.5 cortical slices, isolated using FACS and plated for cell culture. Immunohistochemistry for the $5-\mathrm{HT}_{6}$ receptor was performed using an antibody that specifically recognizes the $5-\mathrm{HT}_{6}$ receptor in $293 \mathrm{~T}$ cells over-expressing $5-\mathrm{HT}_{6}-$ EGFP (Figure $3 e$ ). Using this antibody, we observed that $\mathrm{E} 17.5 \mathrm{TOM}+$ cells at day in vitro 1 display $5-\mathrm{HT}_{6}$ receptor immunoreactivity (Figure $3 \mathrm{f}$ ) as well as FACS-isolated GAD65-GFP + cells (Figure $3 \mathrm{~g}$ ). Immunohistochemistry for the $5-\mathrm{HT}_{6}$ receptor on coronal sections at $\mathrm{E} 17.5$ revealed strong $5-\mathrm{HT}_{6}$ receptor immunoreactivity in the VZ/SVZ as well as in the cortical plate (Figures $3 \mathrm{~h}, \mathrm{i}$ ). Immunostaining for the $5-\mathrm{HT}_{6}$ receptor persisted at P0.5 across the developing cortex with a more pronounced expression in superficial cortical layers (Figure 3j). Taken together, these data indicate that migrating pyramidal neurons are likely to directly respond to $5-\mathrm{HT}_{6}$ receptor activation.

Activation of the $5-\mathrm{HT}_{6}$ receptor decreases pyramidal neuron migration. To determine whether $5-\mathrm{HT}_{6}$ receptor activation affects pyramidal neuron migration, migrating $\mathrm{E} 17.5 \mathrm{TOM}+$ cells electroporated at E14.5 were exposed to EMD $386088(300 \mu \mathrm{M})$, a specific agonist of the $5-\mathrm{HT}_{6}$ receptor. Single-cell tracking revealed that EMD application significantly reduces the speed of $\mathrm{TOM}+$ radial migration (Figure 4; Supplementary Movie 5). A similar effect of EMD on pyramidal neuron migration was observed in P0.5 TOM + cells electroporated at $\mathrm{E} 16.5$ indicating that $5-\mathrm{HT}_{6}$ receptor activation slows the migration of pyramidal neurons populating superficial layers of the neocortex (Figure 4d; Supplementary Movie 6). After washing EMD from the bath medium, TOM + cells monitored at E17.5 and P0.5 gradually resumed radial migration, indicating that the effects of $5-\mathrm{HT}_{6}$ receptor activation on pyramidal migration are reversible (Figures 4c, d).

\section{Excess of serotonin in vivo affects the positioning of} superficial layer cortical neurons. To study the migration and subsequent layer-specific positioning of superficial layer cortical neurons in vivo, we labeled pyramidal neurons at E14.5 in control and SERT ko mice, and analyzed the distribution of TOM + cells at E19.0 in the prospective somatosensory cortex. Quantification of the laminar distribution of TOM-labeled cells at E19.0 revealed that the proportion of TOM-labeled cells in bin 2 (corresponding to prospective layer II/III) was significantly decreased in SERT ko mice (Figures $5 \mathrm{a}-\mathrm{c}$ ). Conversely, a significantly higher percentage of TOM-labeled cells were located in bins 3-4 (corresponding to deeper cortical layers, Figures $5 \mathrm{a}-\mathrm{c}$ ). These data indicate that the positioning of presumptive superficial cortical neurons is affected in vivo in a mouse model with increased extracellular levels of serotonin.

\section{Discussion}

Using in utero electroporation to label neocortical pyramidal neurons in combination with time-lapse imaging, we find that an excess of serotonin significantly decreases the speed of migration of superficial layer cortical pyramidal neurons in cortical slices. The effect of serotonin on neocortical pyramidal migration is reversible and replicated by application of EMD, a specific 5- $\mathrm{HT}_{6}$ receptor agonist. In situ hybridization, quantitative PCR and immunohistochemistry reveal that the $5-\mathrm{HT}_{6}$ receptor is expressed during embryonic cortical development in pyramidal neurons populating superficial cortical layers. Finally, we find that the positioning of superficial layer pyramidal neurons is altered in vivo in SERT ko mice.

Serotonin is detected in the mouse forebrain as early as E10.5 and is mainly produced by the placenta. ${ }^{30}$ Later during development, when superficial layer neocortical pyramidal neurons are migrating radially to reach the cortical plate, serotonin is mainly produced by raphe fibers. ${ }^{30}$ Furthermore, at this time of development, the intermediate zone of the cortical anlage receives the innervation of thalamo-cortical axons that express high levels of SERT allowing them to actively reuptake serotonin from the extracellular space. ${ }^{31,32}$ Importantly, the developmental expression of SERT is also observed in the common marmoset (Callithrix jacchus) ${ }^{33}$ and in the human cortical anlage as early as gestational week $10 .^{34}$ It is thus likely that developmental SERT blockade could 

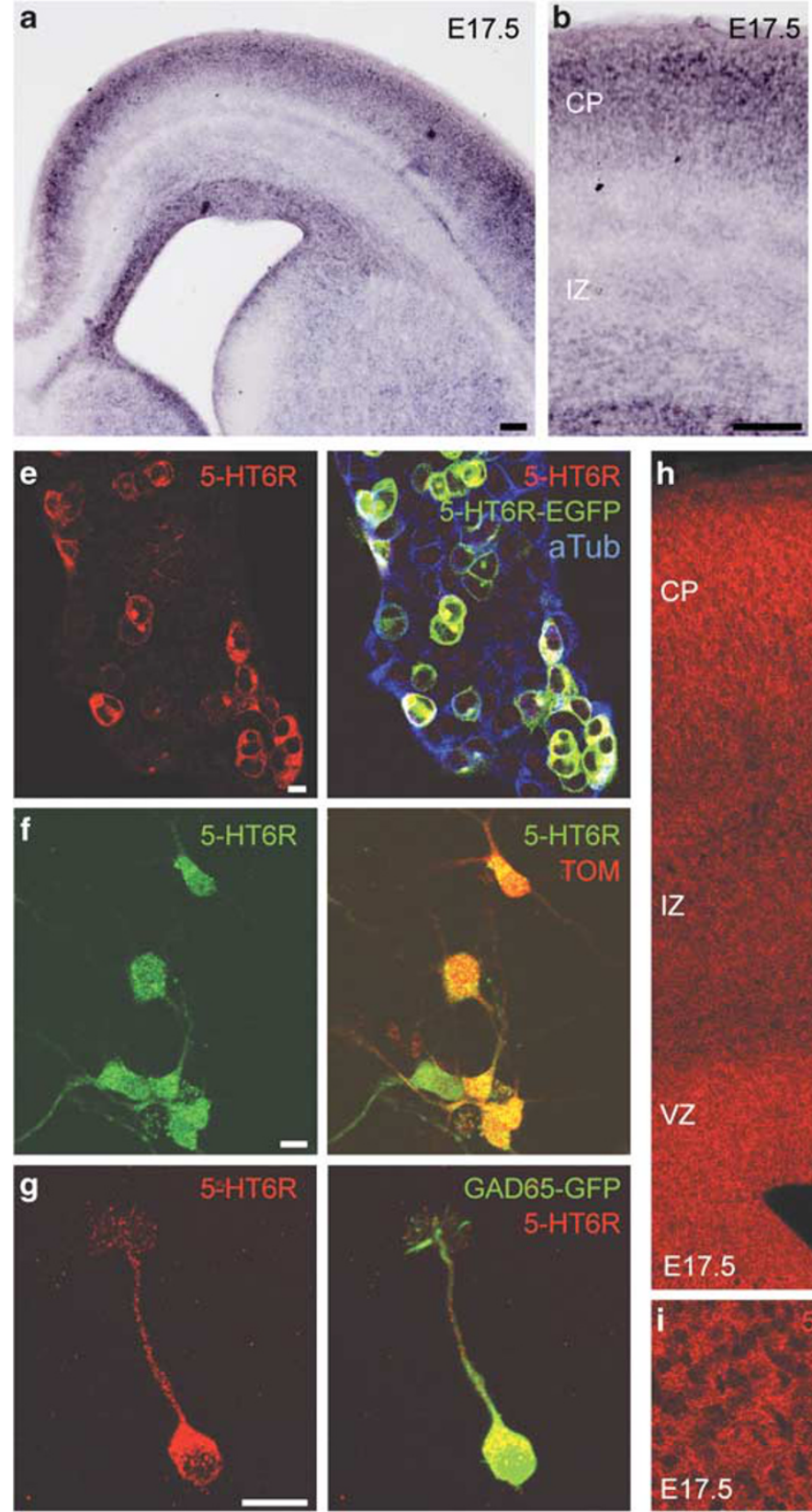
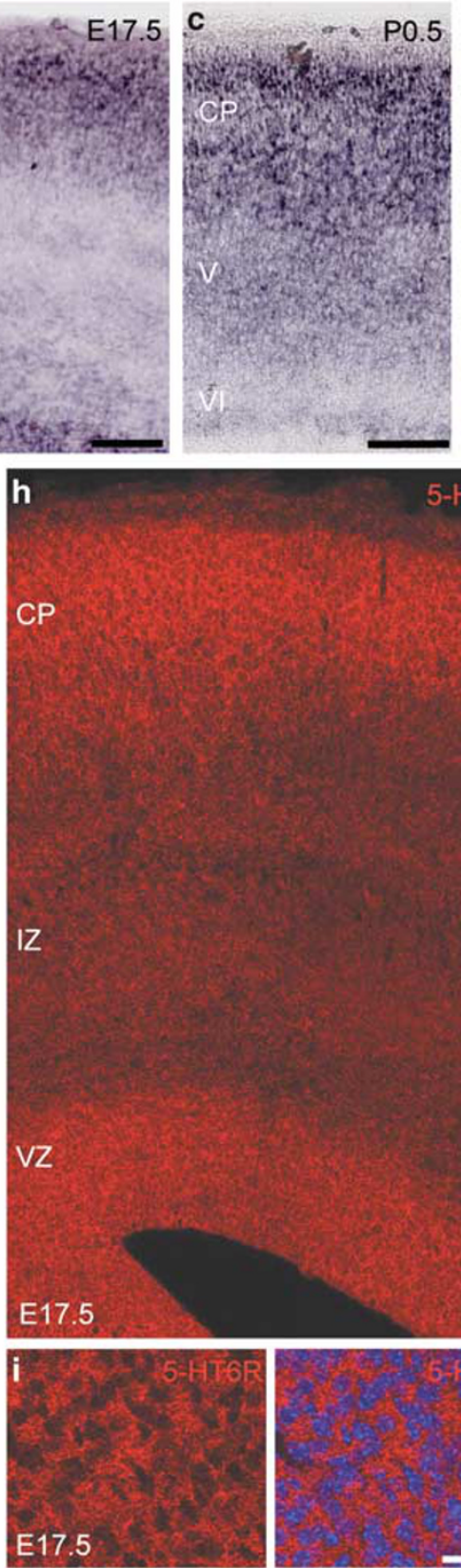

d

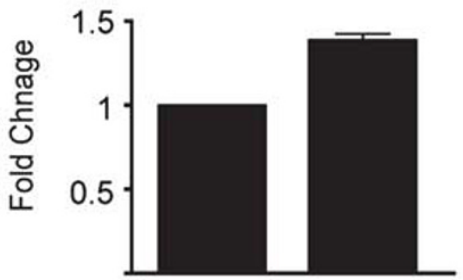

E17.5

P0.5

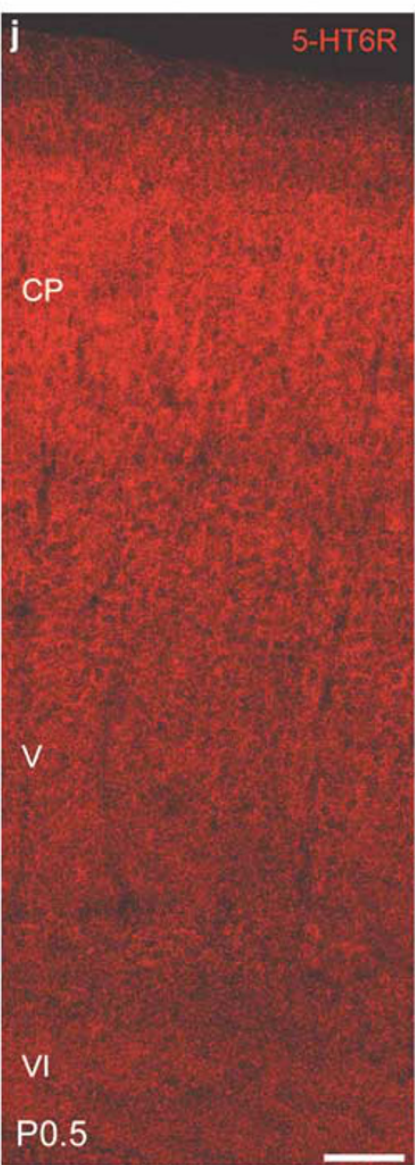

Figure 3 The $5-\mathrm{HT}_{6}$ receptor is expressed in pyramidal neurons during cortical development. (a-c) In situ hybridization showing strong expression of the $5-\mathrm{HT}_{6}$ receptor at E17.5 (a, b) and P0.5 (c). (d) Quantitative PCR graph showing no significant fold change in the cortical expression of the 5-HT 6 receptor. (e) Confocal image showing that the $5-\mathrm{HT}_{6}$ receptor antibody used in this study specifically recognizes $293 \mathrm{~T}$ cells transfected with a $5-\mathrm{HT}_{6}-$ EGFP-over-expressing plasmid. (f, $\mathbf{g}$ ) Confocal images showing that TOM + neurons (f) and GAD65-GFP + cells (g) express the 5- $\mathrm{HT}_{6}$ receptor at day in vitro 1 in cortical cultures. TOM + cells were electroporated at E14.5 in GAD-65-GFP mice, and cortical cultures were prepared at E17.5. (h-j) Composite confocal images showing strong $5-\mathrm{HT}_{6}$ receptor immunoreactivity at E17.5 in the cortical plate (i) and in the ventricular zone (VZ)/SVZ (h) and in superficial cortical layers at P0.5 (j). Scale bars: $100 \mu \mathrm{m}$ for a-c, $10 \mu \mathrm{m}$ for e-g, $50 \mu \mathrm{m}$ for h-j. GFP, GAD65-GFP; Hst, Hoechst; aTub, acetylated tubulin.

lead to pathological excess of serotonin across species during the process of pyramidal neuron migration.

Excess of serotonin is likely to impact neocortical pyramidal neuron migration through the activation of specific serotonin receptors. In a previous study, we have reported that GABAergic interneurons express the $5-\mathrm{HT}_{6}$ receptor, and that activation of this receptor mimics the effects of serotonin application on the regulation of their migration. In this study, we have investigated in more detail the developmental expression of the $5-\mathrm{HT}_{6}$ receptor using in situ hybridization, quantitative PCR and immunohistochemistry. Our results indicate that the $5-\mathrm{HT}_{6}$ receptor is expressed throughout the late embryonic developing cortex in accordance with the pattern of expression reported for the GENSAT $5-\mathrm{HT}_{6}$ BAC EGFP reporter line (http://gensat.org). Our data also reveal that neocortical pyramidal neurons express the $5-\mathrm{HT}_{6}$ 

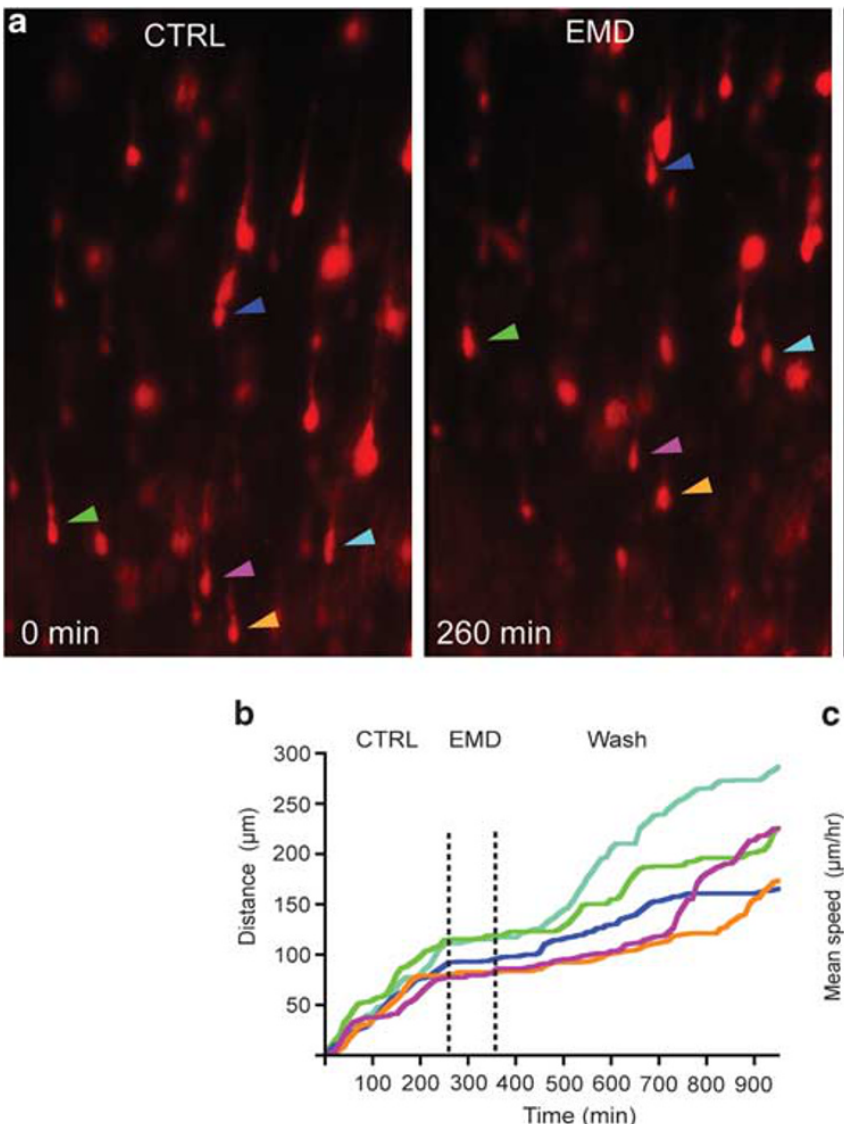

C
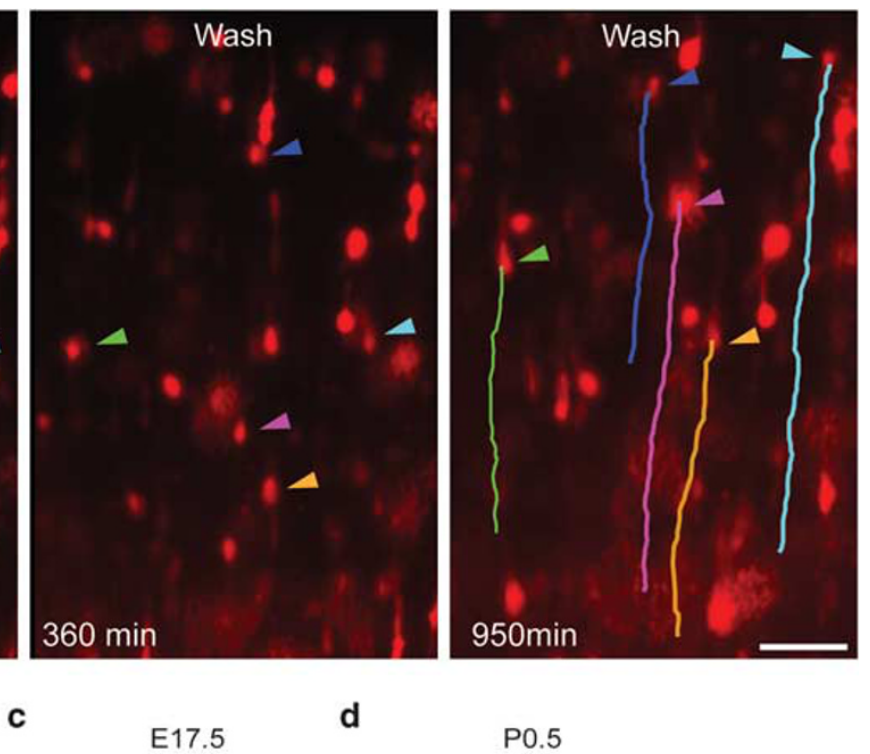

C
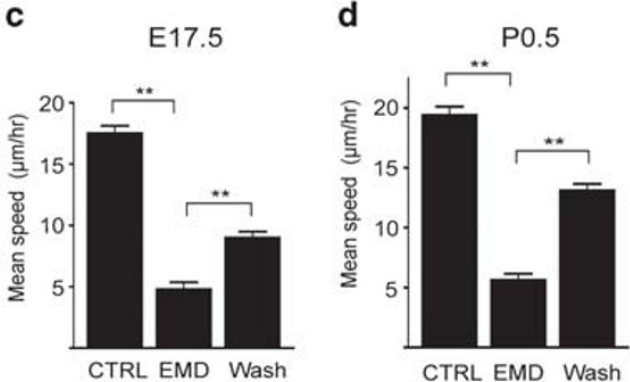

Figure 4 Activation of the $5-\mathrm{HT}_{6}$ receptor decreases pyramidal neuron migration. (a) Epifluorescent time-lapse images taken from a 12-hour time-lapse sequence showing that application of EMD $(300 \mu \mathrm{M})$, a specific $5-\mathrm{HT}_{6}$ receptor agonist, decreases the migration of TOM + neurons (arrowheads) in a P0.5 cortical slice and that this effect is reversible after washing EMD from the medium. Superposed color lines represent migratory tracks. (b) Graph showing the migratory distance traveled by TOM + cells indicated in panel a. Note that cells halt their migration during EMD application and gradually resumes migration after the wash. (c, d) Graphs showing that the mean migratory speed of E17.5 TOM + cells (c) and P0.5 TOM + cells (d) significantly decreases after EMD application and is partially restored after EMD wash. White boxed area depicts a higher magnification image. ${ }^{\star *} P<0.01$. GFP, GAD65-GFP. Scale bars: $50 \mu \mathrm{m}$ for a.
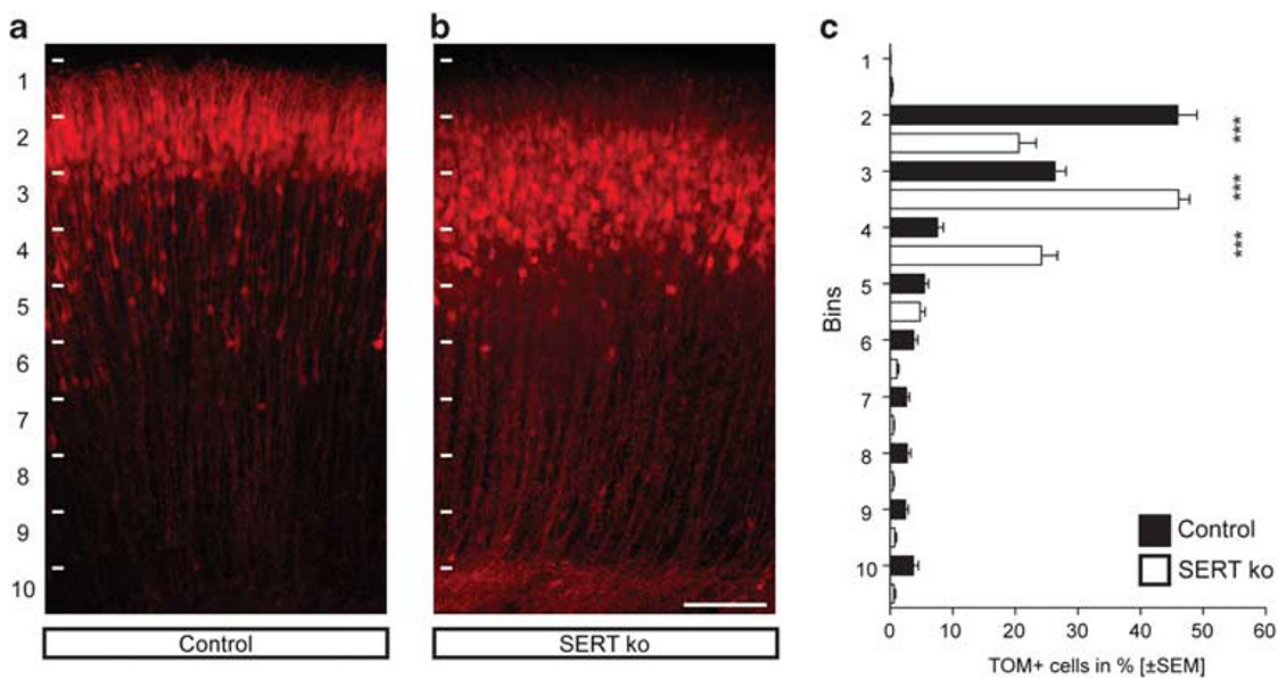

Figure 5 The distribution of superficial layer cortical neurons is altered in SERT knockout mice. (a, b) Epifluorescent images of a E19.0 coronal section showing that the distribution of TOM-labeled neurons in the somatosensory cortex is altered in SERT ko mice compared with wild-type mice. Pyramidal neurons were labeled using in utero electroporation of a TOM + -expressing plasmid in the ventricular zone (VZ) at E14.5. (c) Graph showing that the percentage of TOM-labeled cells is significantly decreased in superficial cortical layers (bin 2) and significantly increased in bin 3-4 in SERT ko mice compared with wild-type mice. ${ }^{\star \star \star} P<0.001$. Scale bars: $50 \mu \mathrm{m}$. 
receptor, indicating that serotonin could act directly through this receptor to regulate their migration. Using time-lapse imaging to monitor the migration of neocortical pyramidal neurons, we find that activation by a specific agonist of the $5-\mathrm{HT}_{6}$ receptor replicates the effects of serotonin. The mechanisms downstream of $5-\mathrm{HT}_{6}$ receptor activation in neocortical pyramidal neurons are currently unknown. The $5-\mathrm{HT}_{6}$ receptor is a G-coupled protein receptor positively linked to adenylate cyclase. Increased cyclic AMP levels have been shown to reduce neuronal migration in invertebrates ${ }^{35}$ and in the mammalian cerebellum, ${ }^{36}$ a mechanism associated with a reduction of intracellular $\mathrm{Ca}^{2+}$ transients. A similar mechanism could follow $5-\mathrm{HT}_{6}$ receptor activation, but other downstream transduction pathways are reported and involve $\mathrm{Fyn}^{37}$ and $\mathrm{JAB1}{ }^{38}$ It is thus likely that the effects of $5-\mathrm{HT}_{6}$ receptor activation on neocortical pyramidal cell migration are mediated by various complementary transduction pathways that need to be further investigated.

SERT ko mice display high levels of extracellular serotonin, ${ }^{39}$ and show a broad range of behavioral alterations ranging from anxiety-like and depressive-like behaviors to autistic-like behaviors. ${ }^{40,41}$ Although the general brain morphology of SERT ko mice appears grossly normal, quantification of the thickness of cortical layers revealed significant alterations, ${ }^{42}$ suggesting early developmental insults in neocortical circuit formation. Some of these changes could be due to alterations in interneuron positioning as described in superficial cortical layers of the SERT ko mice ${ }^{6}$ but also due to alterations in the positioning of superficial layer neocortical neurons as found in this study. The alterations in neocortical pyramidal migration described in this work adds to the growing body of data demonstrating that excessive levels of serotonin during critical developmental periods alters basic cellular processes involved in the formation of neocortical circuits. How these early-life developmental alterations are causally related to the broad range of psychiatric-relevant phenotypes detected in adulthood remains to be investigated. It is likely that early alterations in neuronal migration and thalamocortical axon wiring may be more related to autistic-like features as observed in constitutive SERT ko mice, ${ }^{41}$ whereas alterations in amygdalo-prefrontal limbic circuitry may occur at later developmental steps and be more related to stressrelated phenotypes. ${ }^{43}$ Results obtained in SERT deficient rodent models are relevant for the understanding of human psychiatric disorders. In humans, the hypofunctional s-allele moderates a wide range of behavioral dimensions ranging from autism, depression, neurotic personality traits and differences in emotional and cognitive processing. ${ }^{19,21,23,44,45}$ Several arguments suggest that the behavioral consequences associated to SERT hypofunction/blockade in humans may have a developmental origin. First, many studies in human ${ }^{17,19,21,23,46,47}$ and nonhuman primates ${ }^{18,20,22,48,49}$ reveal that the s-allele interacts with developmental adversity that occurs either during pregnancy or the early postnatal period. Second, structural brain imaging studies in humans and nonhuman primates carrying the s-allele reveal gray matter volume differences in medial limbic regions, which are suggestive of a developmental origin. ${ }^{50,51}$ Finally, selective serotonin reuptake inhibitors exposure during pregnancy affects neurobehavioral development ${ }^{52}$ and increases the risk to autism spectrum disorders. ${ }^{26}$ Taken together, rodent, human and non-human primate data strongly suggest that the developmental set point for 5-HT homeostasis impacts neural circuit formation and can lead to increased risk for psychiatricrelevant phenotypes in adulthood. Further studies are needed to more precisely map the developmental timing of SERT deficiency with altered circuit formation and behavioral outcomes.

\section{Conflict of interest}

The authors declare no conflict of interest.

Acknowledgements. We wish to thank $\mathrm{C}$ Aubry for technical assistance. This work was supported by Swiss National Foundation grants (PP00P3_128379 and the NCCR Synapsy), the Thorn Foundation, the Mercier Foundation and a NARSAD award (The brain and Behaviour Research Fund) (AGD).

1. Thompson BL, Levitt $P$. The clinical-basic interface in defining pathogenesis in disorders of neurodevelopmental origin. Neuron 2010; 67: 702-712.

2. Marin O, Valiente M, Ge X, Tsai LH. Guiding neuronal cell migrations. Cold Spring Harb Protoc 2010; 2: a001834

3. Valiente M, Marin O. Neuronal migration mechanisms in development and disease. Curr Opin Neurobiol 2010; 20: 68-78.

4. Gaspar $P$, Cases $O$, Maroteaux $L$. The developmental role of serotonin: news from mouse molecular genetics. Nat Rev Neurosci 2003; 4: 1002-1012.

5. Persico AM, Mengual E, Moessner R, Hall FS, Revay RS, Sora I et al. Barrel pattern formation requires serotonin uptake by thalamocortical afferents, and not vesicular monoamine release. J Neurosci 2001; 21: 6862-6873.

6. Riccio O, Potter G, Walzer C, Vallet P, Szabo G, Vutskits $L$ et al. Excess of serotonin affects embryonic interneuron migration through activation of the serotonin receptor 6 . Mol Psychiatry 2009; 14: 280-290.

7. Boehme SA, Lio FM, Sikora L, Pandit TS, Lavrador K, Rao SP et al. Cutting edge: serotonin is a chemotactic factor for eosinophils and functions additively with eotaxin. $\mathrm{J}$ Immunol 2004; 173: 3599-3603.

8. Day RM, Agyeman AS, Segel MJ, Chevere RD, Angelosanto JM, Suzuki YJ et al. Serotonin induces pulmonary artery smooth muscle cell migration. Biochem Pharmacol 2006; 71: 386-397.

9. Tamura K, Kanzaki T, Saito Y, Otabe M, Saito $Y$, Morisaki N. Serotonin (5-hydroxytryptamine, 5-HT) enhances migration of rat aortic smooth muscle cells through 5-HT2 receptors. Atherosclerosis 1997; 132: 139-143.

10. Matsusaka S, Wakabayashi I. 5-Hydroxytryptamine as a potent migration enhancer of human aortic endothelial cells. FEBS Lett 2005; 579: 6721-6725.

11. Moiseiwitsch JR, Lauder JM. Serotonin regulates mouse cranial neural crest migration. Proc Natl Acad Sci USA 1995; 92: 7182-7186.

12. Vitalis T, Cases O, Passemard S, Callebert J, Parnavelas JG. Embryonic depletion of serotonin affects cortical development. Eur J Neurosci 2007; 26: 331-344.

13. Kindt KS, Tam T, Whiteman S, Schafer WR. Serotonin promotes G(0)-dependent neuronal migration in Caenorhabditis elegans. Curr Biol 2002; 12: 1738-1747.

14. Noorlander CW, Ververs FF, Nikkels PG, van Echteld CJ, Visser GH, Smidt MP. Modulation of serotonin transporter function during fetal development causes dilated heart cardiomyopathy and lifelong behavioral abnormalities. PLOS ONE 2008; 3: e2782.

15. Ansorge MS, Zhou M, Lira A, Hen R, Gingrich JA. Early-life blockade of the 5-HT transporter alters emotional behavior in adult mice. Science 2004; 306: 879-881.

16. Ansorge MS, Morelli E, Gingrich JA. Inhibition of serotonin but not norepinephrine transport during development produces delayed, persistent perturbations of emotional behaviors in mice. J Neurosci 2008; 28: 199-207.

17. Pluess M, Velders FP, Belsky J, van ljzendoorn MH, Bakermans-Kranenburg MJ, Jaddoe VW et al. Serotonin transporter polymorphism moderates effects of prenatal maternal anxiety on infant negative emotionality. Biol Psychiatry 2010; 69: 520-525.

18. Suomi SJ. Risk, resilience, and gene $x$ environment interactions in rhesus monkeys Ann N Y Acad Sci 2006; 1094: 52-62.

19. Uher R, McGuffin $P$. The moderation by the serotonin transporter gene of environmental adversity in the aetiology of mental illness: review and methodological analysis. Mol Psychiatry 2008; 13: 131-146.

20. Bennett AJ, Lesch KP, Heils A, Long JC, Lorenz JG, Shoaf SE et al. Early experience and serotonin transporter gene variation interact to influence primate CNS function. Mol Psychiatry 2002; 7: 118-122.

21. Caspi A, Hariri AR, Holmes A, Uher R, Moffitt TE. Genetic sensitivity to the environment: the case of the serotonin transporter gene and its implications for studying complex diseases and traits. Am J Psychiatry 2010; 167: 509-527. 
22. Champoux M, Bennett A, Shannon C, Higley JD, Lesch KP, Suomi SJ. Serotonin transporter gene polymorphism, differential early rearing, and behavior in rhesus monkey neonates. Mol Psychiatry 2002; 7: 1058-1063.

23. Karg K, Burmeister M, Shedden K, Sen S. The serotonin transporter promoter variant (5-HTTLPR), stress, and depression meta-analysis revisited: evidence of genetic moderation. Arch Gen Psychiatry 2011; 68: 444-454.

24. Brune CW, Kim SJ, Salt J, Leventhal BL, Lord C, Cook EHJ. 5-HTTLPR genotype-specific phenotype in children and adolescents with autism. Am J Psychiatry 2006; 163 2148-2156

25. Wassink TH, Hazlett HC, Epping EA, Arndt S, Dager SR, Schellenberg GD et al. Cerebra cortical gray matter overgrowth and functional variation of the serotonin transporter gene in autism. Arch Gen Psychiatry 2007; 64: 709-717.

26. Croen LA, Grether JK, Yoshida CK, Odouli R, Hendrick V. Antidepressant use during pregnancy and childhood autism spectrum disorders. Arch Gen Psychiatry 2011 e-pub ahead of print 4 July 2011; doi:10.1001/archgenpsychiatry.2011.73.

27. Berbari NF, Johnson AD, Lewis JS, Askwith CC, Mykytyn K. Identification of ciliary localization sequences within the third intracellular loop of $\mathrm{G}$ protein-coupled receptors Mol Biol Cell 2008; 19: 1540-1547.

28. Niquille M, Garel S, Mann F, Hornung JP, Otsmane B, Chevalley S et al. Transient neuronal populations are required to guide callosal axons: a role for semaphorin $3 \mathrm{C}$. PLOS Biol 2009; 7: e1000230.

29. Chen G, Sima J, Jin M, Wang KY, Xue XJ, Zheng W et al. Semaphorin-3A guides radial migration of cortical neurons during development. Nat Neurosci 2008; 11: $36-44$

30. Bonnin A, Goeden N, Chen K, Wilson ML, King J, Shih JC et al. A transient placental source of serotonin for the fetal forebrain. Nature 2011; 472: 347-350.

31. Lebrand C, Cases O, Adelbrecht C, Doye A, Alvarez C, El Mestikawy S et al. Transient uptake and storage of serotonin in developing thalamic neurons. Neuron 1996; 17: 823-835.

32. Narboux-Neme N, Pavone LM, Avallone L, Zhuang X, Gaspar P. Serotonin transporter transgenic (SERT(cre)) mouse line reveals developmental targets of serotonin specific reuptake inhibitors (SSRIs). Neuropharmacology 2008; 55: 994-1005.

33. Lebrand C, Gaspar P, Nicolas D, Hornung JP. Transitory uptake of serotonin in the developing sensory pathways of the common marmoset. J Comp Neurol 2006; 499 677-689.

34. Verney C, Lebrand C, Gaspar P. Changing distribution of monoaminergic markers in the developing human cerebral cortex with special emphasis on the serotonin transporter. Anat Rec 2002; 267: 87-93

35. Haase A, Bicker G. Nitric oxide and cyclic nucleotides are regulators of neuronal migration in an insect embryo. Development 2003; 130: 3977-3987.

36. Kumada $\mathrm{T}$, Lakshmana MK, Komuro $\mathrm{H}$. Reversal of neuronal migration in a mouse mode of fetal alcohol syndrome by controlling second-messenger signalings. J Neurosci 2006 26: 742-756.

37. Yun HM, Kim S, Kim HJ, Kostenis E, Kim JI, Seong JY et al. The novel cellular mechanism of human 5-HT6 receptor through an interaction with Fyn. J Biol Chem 2007; 282: 5496-5505

38. Yun HM, Baik JH, Kang IS, Jin C, Rhim H. Physical interaction of Jab1 with human serotonin $6 \mathrm{G}$-protein-coupled receptor and their possible roles in cell survival. J Biol Chem 2010; 285: 10016-10029
39. Mathews TA, Fedele DE, Coppelli FM, Avila AM, Murphy DL, Andrews AM. Gene dosedependent alterations in extraneuronal serotonin but not dopamine in mice with reduced serotonin transporter expression. J Neurosci Methods 2004; 140: 169-181.

40. Murphy DL, Lesch KP. Targeting the murine serotonin transporter: insights into human neurobiology. Nat Rev Neurosci 2008; 9: 85-96.

41. Moy SS, Nadler JJ, Young NB, Nonneman RJ, Grossman AW, Murphy DL et al. Social approach in genetically-engineered mouse lines relevant to autism. Genes Brain Behav 2008; 8: 129-142.

42. Altamura C, Dell'Acqua ML, Moessner R, Murphy DL, Lesch KP, Persico AM. Altered neocortical cell density and layer thickness in serotonin transporter knockout mice: a quantitation study. Cereb Cortex 2007; 17: 1394-1401.

43. Wellman CL, Izquierdo A, Garrett JE, Martin KP, Carroll J, Millstein R et al. Impaired stresscoping and fear extinction and abnormal corticolimbic morphology in serotonin transporter knock-out mice. J Neurosci 2007; 27: 684-691.

44. Munafo MR, Brown SM, Hariri AR. Serotonin transporter (5-HTTLPR) genotype and amygdala activation: a meta-analysis. Biol Psychiatry 2008; 63: 852-857.

45. Canli T, Lesch KP. Long story short: the serotonin transporter in emotion regulation and social cognition. Nat Neurosci 2007; 10: 1103-1109.

46. Barry RA, Kochanska G, Philibert RA. G $\times E$ interaction in the organization of attachment: mothers' responsiveness as a moderator of children's genotypes. J Child Psychol Psychiatry 2008; 49: 1313-1320.

47. Kochanska G, Philibert RA, Barry RA. Interplay of genes and early mother-child relationship in the development of self-regulation from toddler to preschool age. J Child Psychol Psychiatry 2009; 50: 1331-1338.

48. Kraemer GW, Moore CF, Newman TK, Barr CS, Schneider ML. Moderate level fetal alcohol exposure and serotonin transporter gene promoter polymorphism affect neonatal temperament and limbic-hypothalamic-pituitary-adrenal axis regulation in monkeys. Biol Psychiatry 2008; 63: 317-324.

49. Barr CS, Newman TK, Shannon C, Parker C, Dvoskin RL, Becker ML et al. Rearing condition and rh5-HTTLPR interact to influence limbic-hypothalamic-pituitary-adrenal axis response to stress in infant macaques. Biol Psychiatry 2004; 55: 733-738.

50. Pezawas L, Meyer-Lindenberg A, Drabant EM, Verchinski BA, Munoz KE, Kolachana BS et al. 5-HTTLPR polymorphism impacts human cingulate-amygdala interactions: a genetic susceptibility mechanism for depression. Nat Neurosci 2005; 8: 828-834.

51. Jedema HP, Gianaros PJ, Greer PJ, Kerr DD, Liu S, Higley JD et al. Cognitive impact of genetic variation of the serotonin transporter in primates is associated with differences in brain morphology rather than serotonin neurotransmission. Mol Psychiatry 2009; 15: 512-522.

52. Mulder EJ, Ververs FF, de Heus R, Visser GH. Selective serotonin reuptake inhibitors affect neurobehavioral development in the human fetus. Neuropsychopharmacology 2011; 36: 1961-1971.

Translational Psychiatry is an open-access journal published by Nature Publishing Group. This work is licensed under the Creative Commons Attribution-Noncommercial-No Derivative Works 3.0 Unported License. To view a copy of this license, visit http://creativecommons.org/licenses/by-nc-nd/3.0/

\section{Supplementary Information accompanies the paper on the Translational Psychiatry website (http://www.nature.com/tp)}

